\title{
Eco-Friendly Approach to Control Mosquitos (A. stephensi, C. quinquefasciatus, and A. aegypti) Using Silver Nanoparticle
}

\author{
Jimmandiyur Madhappan Murugan ${ }^{1}$, Mathiyazhagan Narayanan ${ }^{1 *}$, Muthugoundar \\ Subramanian Shivakumar ${ }^{2 *}$, Govindaraju Ramkumar ${ }^{3}$ \\ ${ }^{1}$ PG and Research Centre in Biotechnology, MGR College, Adhiyamaan Educational Research Institute, Hosur, Krishnagiri, Tamilnadu, India \\ ${ }^{2}$ Molecular Entomology Lab, Department of Biotechnology, Periyar University, Salem, Tamilnadu, India \\ ${ }^{3}$ Department of Entomology, Indian council of Agriculture Research Institute, Bangalore, Karnataka, India \\ ${ }^{4}$ Institute for Energy Research, Jiangsu University, Zhenjiang, China
}

Received: 15/10/2020 Accepted: 03/11/2020 Published: 20/03/2021

\begin{abstract}
The available controlling agents for mosquito vectors are chemical insecticides and the frequent usage of these insecticides creating resistance among mosquito vectors and environmental pollutions. Thus, the study was designed to synthesize and characterize the Ag nanoparticles (AgNPs) through a methanol leaf extract of Ocimum canum and find the larvicidal prospective of the AgNPs on the $4^{\text {th }}$ instar larvae of Anopheles stephensi, Culex quinquefasciatus, and Aedes aegypti. The obtained outcomes show that the methanol leaf extract of $O$. canum was effectively reduced the silver ions and produce constant silver nanoparticles. It was characterized and confirmed by various scientific techniques such as UV-vis spectrum, XRD, SEM, FT-IR and EDaX. Various concentrations (10, 50, 150, 200, and $250 \mathrm{ppm}$ ) of characterized nanoparticles were tested for larvicidal activity. The premier larval death was observed at $24 \mathrm{~h}$ of treatment on $A$. aegypti with LC50 $=17.03 \mathrm{ppm}$, followed by $C$. quinquefasciatus with LC50 $=14.89 \mathrm{ppm}$ of methanol extract of $O$. canum and no death was noticed on A. stephensi. The LD90 value for A. aegypti and C. quinquefasciatus were 24.18 \& 20.65 ppm respectively. Hence, the Ag nanoparticles produced from methanol leaf extract of $O$. canum retains efficiency to control A. aegypti and $C$. quinquefasciatus. Thus, it might support partially to replace the chemical insecticide which used against these vectors and might contribute to reduce environmental pollution.
\end{abstract}

Keywords: O. canum, methanol extract, Biodegradable AgNPs, larvicidal activity, mosquito vectors

\section{Introduction}

The frequent usage of chemical insecticides and pesticides (pyrethroid) is creating severe environmental pollutions such as soil and water pollutions [1-5]. In growing countries like India, the management of mosquitos and other insect vectors are still depends on chemical insecticides [6-9]. Thus, it might create environmental pollution and creates insecticide resistance among mosquitos. Since the mosquitos are the most significant insect which acts as a notable vector to cause several kinds of virus-borne infections in many countries, transmit disease approximately seven hundred lakhs people in each year in the entire globe and it crossing more than 40 lakhs people in each year in India [10-12]. Among several mosquito species, Anopheles stephensi, Culex quinquefasciatus, and Aedes aegypti are the responsible vector for causing filariasis, dengue fever, malaria, chikungunya, zika virus infection, etc. in numerous Asian countries [13-15]. In India, mosquito routed diseases happen more frequently with some common vectors such as, A. aegypti acts as a vector, which can cause yellow fever, dengue, chikungunya, etc. A. subpictus and $C$. quinquefasciatus are respectively acted as a vector for malaria and lymphatic filariasis on more than 50 lakhs people in India [16-18]. This caused an annual financial defeat of 15 million US dollars [19-21]. The most active vector control is usually counted on the synthetic pesticide practices pointing larvae of mosquito vector [22-24]. The recurrent usage of these synthetic pesticides promotes numerous ecological threats and develops resistance among insects, pests, and toxic effects on non-target organisms [25-27].

Recently researchers are focused on nanoparticles based resolution for this foresaid disputes. The potentiality and possible utilization of this modern material science completely rely on their morphological nature, such as size and shape [28$30]$. It has been related to the chemical structure and physical nature of mother chemicals considered for nanoparticle fabrication [31, 32]. These nanoparticles (NPs) are having multiple-face, thus can be used in numerous areas of biological (antimicrobials, biosensors, drug delivery, bioplastics, etc.) and material sciences (catalysts, chemical sensors, etc.) field [33, 33]. The metal-based nanoparticles are extensively utilized in the medical field to deliver the drug exactly the targeted place and without the interaction of adjacent healthy cells and surprisingly, in recent years researchers are focused to diminish

*Corresponding author: Dr. Mathiyazhagan Narayanan, PG and Research Centre in Biotechnology, MGR College, Adhiyamaan Educational Research Institute, Hosur, Krishnagiri, Tamilnadu, India. E-mail: mathimicro@gmail.com and Dr. Shivakumar Muthugoundar Subramanian, Molecular Entomology Lab, Department of Biotechnology, Periyar University, Salem, Tamilnadu, India. E-mail: skentomol@gmail.com 
the spreading of disease through mosquitos vector by nanoparticles synthesized by plant extracts and microbes $[7,18]$. The plant-based nanoparticle production is more comfortable than other biological procedures for huge scale production in a short duration [8, 19]. Even though, the production of AgNPs with larvicidal efficiency and adult mosquito slaughter efficiency is still a challenge [9]. The phytochemical contents of plants have the prospective to break the complexed material to a simple form, it could be useful to various biological-based usages in multiple fields.

The oxidation and reduction approaches are routinely engaged in $\mathrm{Ag}$ and other metals-based nanoparticles production through reducing chemical agents [2, 20, 21, 33]. However, these chemical-based approaches have some hinders and toxic nature on the regular consumption of nanoparticles in biological applications. Thus this research work was designed to reveal the green fabrication of biodegradable AgNPs through methanol leaf extract of $O$. canum and assess their larvicidal and adult slaughter potential on A. Aegypti, A. stephensi, and $C$. quinquefasciatus.

\section{Materials and Methods}

\subsection{Preparation of methanol leaf extract from $O$. canum}

As per the previous study [34], the $O$. canum was chosen for this work. The leaf of $O$. canum was used for the extraction process with methanol solvent as per the protocol of Minjas and Sarda [35] with minor alterations. About $10 \mathrm{~g}$ of fresh leaves of O. canum sample was thoroughly washed with Tween -20 for 3-4 times. The rinsed leaves were sliced into adequate quantities and heated with $100 \mathrm{~mL}$ of methanol solvent in 250 $\mathrm{mL}$ conical flask at $60^{\circ} \mathrm{C}$ for $5 \mathrm{~min}$. The final extract was sieved through Whatman filter paper (No. 1) and preserved at $-20^{\circ} \mathrm{C}$ for supplementary analyses.

\subsection{Synthesis of Ag nanoparticles}

The AgNPs were produced from $O$. canum as per the methodology of Huang et al. [36], concisely $10 \mathrm{~mL}$ of methanol extract of $O$. canum was treated with $90 \mathrm{~mL}$ of $1 \mathrm{mM} \mathrm{AgNO} 3$ in $250 \mathrm{~mL}$ flask and retained at chamber temperature for 12 mins and perceived the blackish-brown to yellowish-orange color development, it primarily confirms the production of AgNPs.

\subsection{Analyses of AgNPs}

The reduction and structural elucidation of filtered AgNPs was performed by following the methodology of Parthiban et al. [37] and Minjas and Sarda [35] with some modifications.

\subsubsection{UV-Visible Spectrophotometer analysis}

The absorption maxima of reduced AgNPs produced from O. canum was examined through a UV-Vis spectrophotometer (Shimadzu-UV2600I, Japan) at 300-700 nm and functioned at a resolution of $1 \mathrm{~nm}$ at diverse time breaks $(2,4,6, \& 8 \mathrm{hr})$. Briefly, $0.2 \mathrm{~mL}$ of a diluted small aliquot of the sample was spun at $8,000 \mathrm{rpm}$ for $15 \mathrm{~min}$ and the pellet was filtered $(0.40 \mu \mathrm{m})$ and dissolved in distilled water for further characterization study.

\subsubsection{XRD analysis}

The dried nanoparticles were taken for XRD analysis by coated on the grid of XRD [39]. The spectra were documented using Phillips PW 1830 operated at $30 \mathrm{~mA}$ and $40 \mathrm{kV}$ current with $\mathrm{CuK} \alpha 1$ radiation (XRD-LYNXEYE-T detector, Rigaku, Japan).

\subsubsection{Fourier Transform Infrared Spectroscopy (FT-IR) analysis}

The FT-IR analysis was achieved to find promising useful groups accountable for the reduction of AgNO3 into AgNPs. The powdered AgNPs were studied using FT-IR (FT-IR-Model - 400, Japan) with potassium bromide pellets as a contextual over the choice of $400-4000 \mathrm{~cm}^{-1}$.

\subsubsection{SEM-EDaX analysis}

The size and external morphology of the AgNPs was detected by SEM (JEOL- JSM 6390). The size and morphology of the AgNPs sample were observed through $25 \mu \mathrm{L}$ of AgNPs was coated on a copper stub device, worked at hastening energy at $15 \mathrm{kV}$. The EDaX examination was performed by added the dried AgNPs particles on a copper grid coated with carbon and executed on an SEM device with Thermo-EDaX (FEI-Quanta 250) supplement.

\subsection{Mosquito culture}

The most problematic mosquito vectors, such as A. Aegypti, $C$. quinquefasciatus, and A. stephensi were chosen for this study. The mosquito larvae were acquired from the Institute for Vector Control and Zoonosis, Hosur, Tamil Nadu, India. The procured cultures were successfully retained and raised under laboratory conditions [13]. The larvae were raised in clean platters comprising clean water and presented at $28 \pm 1^{\circ} \mathrm{C}$, with $70-80 \%$ of humidity and light and dark photoperiod of 14:10 ratio. Further 3:1 rate of dog biscuit and yeast powder was used as feed for larvae growth.

\subsection{Larvicidal Bioassay}

The WHO [40] protocol was followed to achieve larvicidal bioassay. Briefly, 25 number of $4^{\text {th }}$ instar larvae were used to individual repeats in $249 \mathrm{~mL}$ of water and $1.0 \mathrm{~mL}$ of methanol extract of $O$. canum with various concentrations $(10,50,100$, 150 , and $200 \mathrm{ppm}$ ) and kept for $24 \mathrm{~h}$ in multi vial tray. The same concentrations and setup were performed with Synthesized AgNP. Cypermethrin and water are used for positive and negative control. Control $\left(\mathrm{AgNO}_{3}\right.$ and distilled water separately) was maintained with triplicates of each dosage. After the treatment, the numbers of dead larvae of $A$. Aegypti, A. stephensi, and $C$. quinquefasciatus mosquitoes (acute toxicity) were computed the percentage of mortality was calculated.

\subsection{CDC Bottle Bioassay}

The CDC Bioassay was achieved by following the protocol of Rahuman et al. [38] with some modifications. About $250 \mathrm{~mL}$ glass tubes were coated with the produced AgNPs with various concentrations $(10,50,100,150$, and $200 \mathrm{ppm})$. About 20 numbers of each mosquito were introduced by aspiration into the CDC bottle. Knock-down was recorded at 10-minute intervals for three hours. After the treatment, knock-down and alive mosquitoes were removed and separated from the bottles and kept in discrete paper cups filled with $10 \%$ sucrose solution and kept at insectary for 24 hours. After, 10\% sucrose treatment, adult mosquitos were confirmed and scored as alive or dead. The identified functional dosage level could be useful to study the potential on the field population.

\subsection{Probity Analysis}

The obtained typical larvae and mosquitos' death results were exposed to probity study for computing LC50, LC90 at 95 $\%$ confidence bounds of upper confidence limit (UCL) and lower confidence limit (LCL) values, and chi-square tests were analyzed with SPSS 13.0. 


\section{Results}

\subsection{Synthesis of silver nanoparticle-UV-Spec. analysis} methanol leaf extract of $O$. canum was evaluated and confirmed by UV-Vis spectra studies with 300 to $700 \mathrm{~nm}$ wavelength range. The color was changed from blackish brown to yellowish-orange (Fig. 1A) which initially confirm the production of AgNPs i.e. reduction of Ag salt through methanol leaf extract of $O$. canum. The maximum absorption spectrum was observed at $453 \mathrm{~nm}$ at $8^{\text {th }}$ hour analysis (Fig. 1B). This confirms that the methanol leaf extract of $O$. canum has silver reducing phytochemical ingredients that enhancing the reduction of silver salt.

\subsection{XRD analysis}

The crystalline size and nanostructure of green synthesized AgNPs were observed by employing an X-ray powder diffraction device. The analysis was demonstrated and confirmed through characteristic peaks observed at $2 \theta$ values of $38.08^{\circ}(111)$ in XRD image (Fig. 2). The developed broaden of Bragg's peaks indicates the formation and confirmation of nanoparticles.

\subsection{FT-IR analysis}

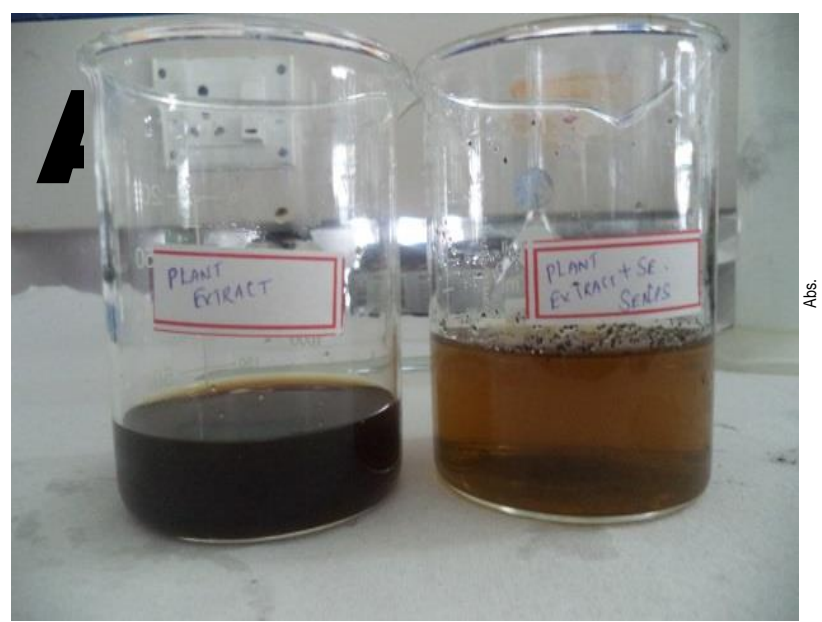

The eco-friendly synthesis of AgNPs from $\mathrm{AgNO} 3$ with

The conceivable band existing in the biomolecule was accountable for the peaks and suitable for capping and competence in stabilizing AgNPs produced by methanol leaf extract of $O$. canum. The spectra showed a strong peak at $1646.24 \mathrm{~cm}^{-1}$ allotted to N-H stretching of 2555.46 with $\mathrm{OH}$ clusters, and the spectra showed an intense peak at $3449 \mathrm{~cm}^{-1}$ consigned to $\mathrm{C}-\mathrm{H}$ stretching binding of $\mathrm{R}-\mathrm{COOH}$. The fragile band was found at $576.16 \mathrm{~cm}^{-1}$ resembles to $\mathrm{C}=\mathrm{C}$ and $\mathrm{C}-\mathrm{N}$ stretching with the alkenes group (Fig. 3).

\subsection{SEM analysis}

The image of SEM analysis of these AgNPs revealed that the particles accumulate over the exterior due to the collaboration of hydrogen with electrostatic bonding among the carbon-based capping particles destined to the AgNPs. The produced AgNPs were in size stretching from $32.75 \mathrm{~nm}-78$. $88 \mathrm{~nm}$, with most of them were spherical, and remains were elongated in shape (Fig. 4).

\subsection{EDaX analysis}

According to the bio-reduction process, energy-dispersive micro and element investigation was performed to gain further perception of the AgNPs employing EDaX techniques. The binding energies of AgNPs were observed at peaks around 72.64. The findings specify that the response product exists in the pure form of silver nanoparticles (Fig. 5).

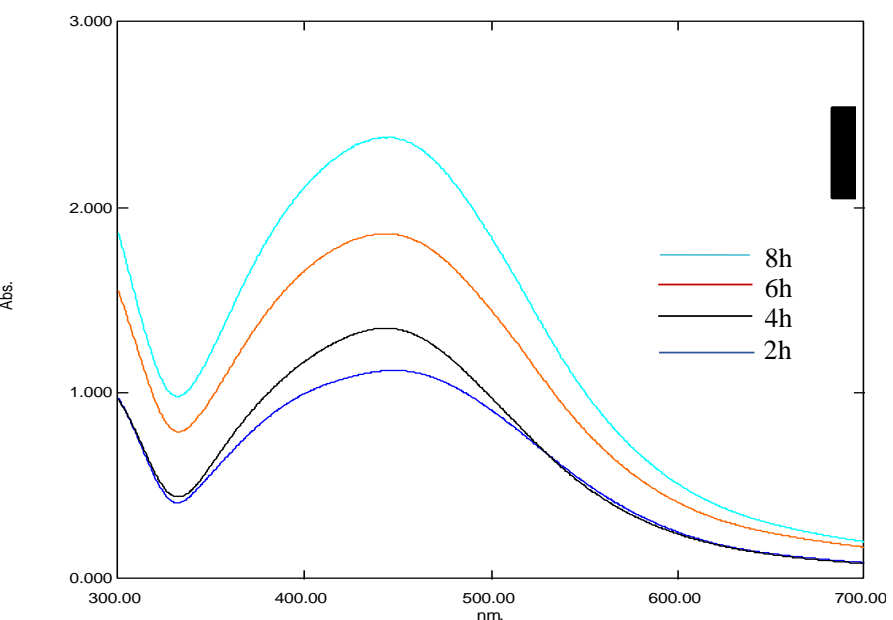

Figure 1: UV-Vis spectra of AgNPs synthesized by methanol extract of $O$. canum: A) Visible color change it's indicated that synthesized silver nanoparticle and B) AgNPs producing a peak at 453nm at different time interval

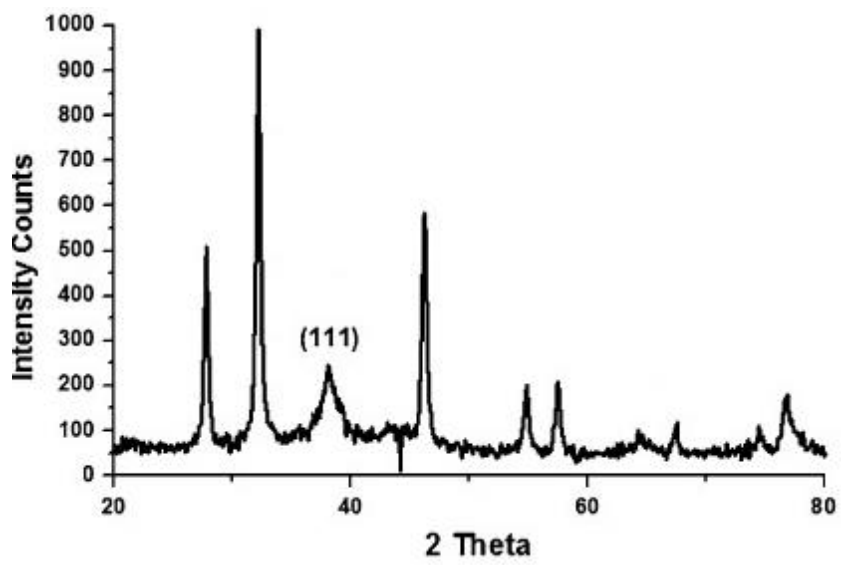

Figure 2: XRD pattern of AgNPs synthesized by methanol extract of $O$. canum 


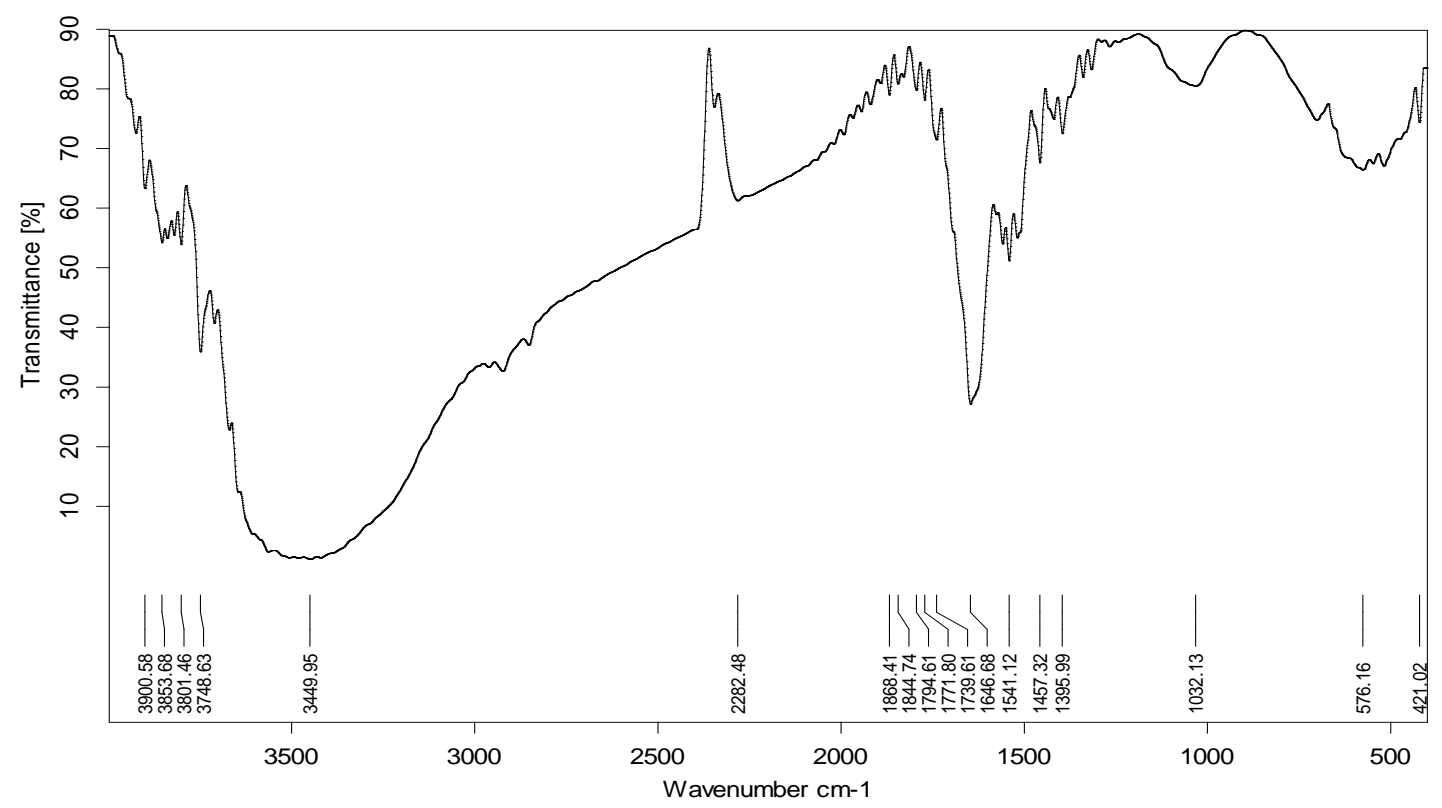

Figure 3: FTIR spectrum of AgNPs synthesized by methanol extract of $O$. canum

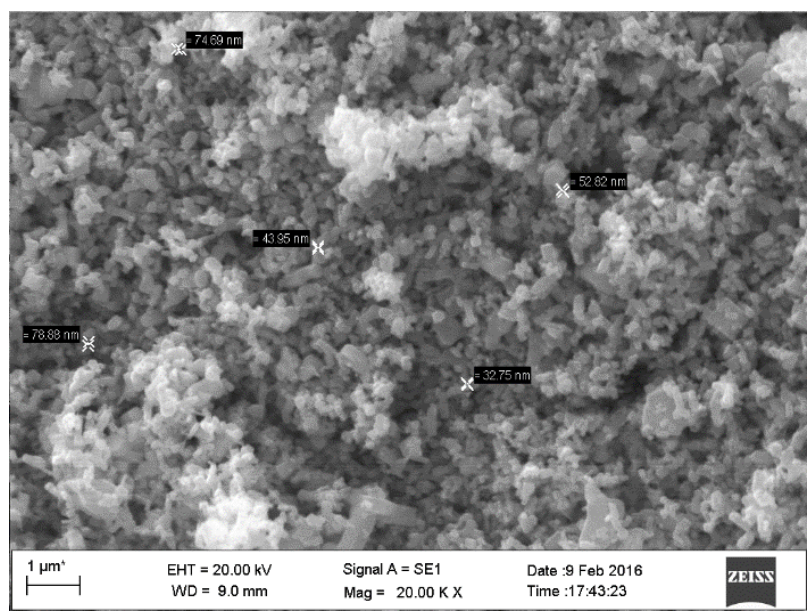

Figure 4: SEM micrographic image of AgNPs synthesized by methanol extract of $O$. canum (Image magnification $\times 20,000$ )

\subsection{Assessment of Larvicidal activity by bioassay}

The death proportion was perceived in the initial $4^{\text {th }}$ instars of $A$. aegypti and $C$. quinquefasciatus with five diverse dosages $(10,50,100,150$, and $200 \mathrm{ppm})$ AgNPs synthesized from methanol leaf extract of $O$. canum to assess the extent larvicidal potential. The findings declared that the maximum larval death was recorded in AgNPs than positive control against $A$. aegypti $(\mathrm{LC50}=17.03$ with $\mathrm{LCL}=14.448 \& \mathrm{UCL}=19.6286 \mathrm{ppm})$, followed by $C$. quinquefasciatus $(\mathrm{LC} 50=14.89$ with $\mathrm{LCL}=$ $11.721 \& \mathrm{UCL}=18.0621 \mathrm{ppm})$ than methanol extract alone (A. aegypti: $\mathrm{LC} 50=52.04$ with $\mathrm{LCL}=49.77 \& \mathrm{UCL}=54.32$ ppm and $C$. quinquefasciatus: $\mathrm{LC} 50=47.19$ with $\mathrm{LCL}=41.22$ $\& \mathrm{UCL}=53.17 \mathrm{ppm}$ ) and aqueous AgNO3 alone (A. aegypti: LC50 $=43.33$ with $\mathrm{LCL}=41.11 \& 45.55 \mathrm{ppm}$ and $C$. quinquefasciatus: $\mathrm{LC} 50=56.10$ with $\mathrm{LCL}=52.80 \& 59.47 \mathrm{ppm}$ ) (Table 1 and 2). There was no noticeable larvicidal activity on A. stephensi by synthesized AgNPs. The LC 90 results were also significant to the results of LC50 larvicidal efficacy of AgNPs synthesized from methanol extract of $O$. canum.

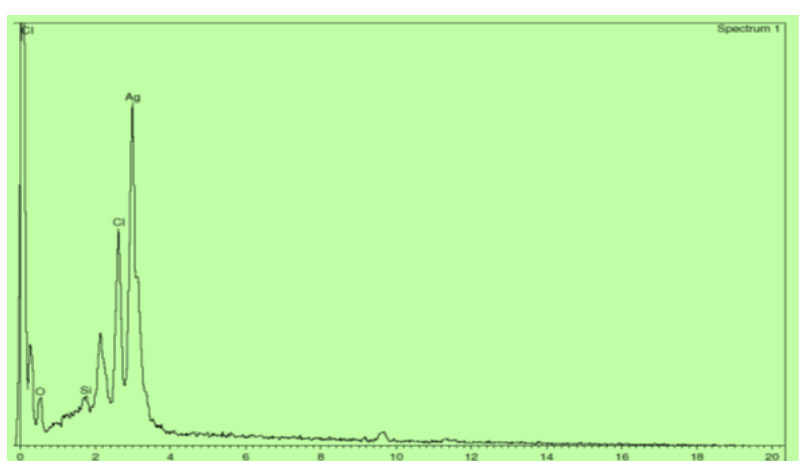

Figure 5: EDaX images of AgNPs derived from O. canum methanolic extract

Table I: Larvicidal activity of methanol extract synthesized AgNPs against fourth instar larvae of $A$. aegypti

\begin{tabular}{|c|c|c|c|c|c|c|c|c|c|}
\hline \multirow{2}{*}{$\begin{array}{l}\text { Name of } \\
\text { mosquito }\end{array}$} & \multirow{2}{*}{ Sample } & \multirow{2}{*}{$\mathbf{n}^{\mathrm{a}}$} & \multirow{2}{*}{$\begin{array}{l}\mathbf{L C}_{50} \\
(\mathbf{p p m})\end{array}$} & \multicolumn{2}{|c|}{ 95\% confidence limit (ppm) } & \multirow[t]{2}{*}{$\begin{array}{l}\begin{array}{l}\mathbf{L C}_{90} \\
(\mathrm{ppm})\end{array} \\
\end{array}$} & \multicolumn{2}{|c|}{ 95\% confidence limit (ppm) } & \multirow[t]{2}{*}{ df } \\
\hline & & & & LCL & UCL & & LCL & UCL & \\
\hline \multirow{4}{*}{ A. aegypti } & AgNPs & 375 & $17.03 \pm 0.42$ & $14.44 \pm 0.82$ & $19.62 \pm 0.86$ & $24.18 \pm 0.15$ & $15.15 \pm 0.51$ & $33.21 \pm 1.5$ & 3 \\
\hline & $\begin{array}{l}\text { Methanol } \\
\text { extract }\end{array}$ & 375 & $52.04 \pm 2.54$ & $49.77 \pm 2.21$ & $54.32 \pm 2.11$ & $65.17 \pm 0.12$ & $61.35 \pm 4.7$ & $69.0 \pm 3.01$ & 3 \\
\hline & $\begin{array}{l}\text { Aqueous } \\
\mathrm{AgNO}_{3}\end{array}$ & 375 & $43.33 \pm 1.71$ & $41.119 \pm 2.15$ & $45.55 \pm 2.11$ & $62.07 \pm 3.9$ & $59.82 \pm 3.62$ & $64.32 \pm 5.1$ & 3 \\
\hline & Positive & 375 & $20.85 \pm 2.28$ & & & $27.98 \pm 2.31$ & & & 3 \\
\hline
\end{tabular}

Legend: $\mathrm{n}^{\mathrm{a}}$ - means Number of larvae (triplicates: $25 \times 3 \times 5$ conc.), $\mathrm{LC}_{50}$ - Lethal concentration $50 \%$ mortality, $\mathrm{LC}_{90}$ - Lethal concentration $90 \%$ mortality, LCL- lower confidence limits, UCL- upper confidence limits, df - degrees of freedom 
Table 2: Larvicidal activity of methanol extract synthesized AgNPs against fourth instar larvae of C. quinquefasitasis

\begin{tabular}{|c|c|c|c|c|c|c|c|c|c|}
\hline \multirow{2}{*}{$\begin{array}{l}\text { Name of } \\
\text { mosquit } \\
\text { o }\end{array}$} & \multirow{2}{*}{ Sample } & \multirow{2}{*}{$\mathbf{n}^{\mathrm{a}}$} & \multirow{2}{*}{$\begin{array}{l}\mathbf{L C}_{50} \\
(\mathbf{p p m})\end{array}$} & \multicolumn{2}{|c|}{ 95\% confidence limit (ppm) } & \multirow[t]{2}{*}{$\begin{array}{l}\mathbf{L C}_{90} \\
(\mathbf{p p m})\end{array}$} & \multicolumn{2}{|c|}{$95 \%$ confidence limit (ppm) } & \multirow{2}{*}{$\begin{array}{l}\text { d } \\
\text { f }\end{array}$} \\
\hline & & & & LCL & UCL & & LCL & UCL & \\
\hline \multirow{4}{*}{$\begin{array}{l}\text { C. } \\
\text { quinquef } \\
\text { asitasis }\end{array}$} & AgNPs & 375 & $14.89 \pm 0.34$ & $11.72 \pm 0.11$ & 18. $06 \pm 0.21$ & $20.65 \pm 1.66$ & $14.39 \pm 0.11$ & $26.91 \pm 1.32$ & 3 \\
\hline & $\begin{array}{l}\text { Methanol } \\
\text { extract }\end{array}$ & 375 & $47.19 \pm 0.86$ & $41.22 \pm 4.39$ & $53.17 \pm 4.72$ & $82.37 \pm 5.9$ & $78.23 \pm 2.14$ & $86.51 \pm 5.1$ & 3 \\
\hline & $\begin{array}{l}\text { Aqueous } \\
\text { AgNO3 }\end{array}$ & 375 & $56.10 \pm 0.31$ & $52.80 \pm 3.11$ & $59.41 \pm 2.63$ & $87.67 \pm 7.24$ & $78.00 \pm 5.65$ & $97.35 \pm 8.12$ & 3 \\
\hline & Positive & 375 & $18.18 \pm 3.78$ & & & $25.21 \pm 3.11$ & & & 3 \\
\hline
\end{tabular}

Legend: $\mathrm{n}^{\mathrm{a}}$ - means Number of larvae (triplicates: $25 \times 3 \times 5$ conc.), $\mathrm{LC}_{50}$ - Lethal concentration $50 \%$ mortality, LC $90^{-}$Lethal concentration $90 \%$ mortality, LCL- lower confidence limits, UCL- upper confidence limits, df - degrees of freedom

Table 3: CDC Bottle Bioassay: Efficiency of methanol leaf extract synthesized AgNPs against A. aegypti

\begin{tabular}{|c|c|c|c|c|c|c|c|c|c|}
\hline \multirow{2}{*}{$\begin{array}{l}\text { Name of } \\
\text { mosquito }\end{array}$} & \multirow{2}{*}{ Sample } & \multirow[t]{2}{*}{$\mathbf{n}^{\mathrm{a}}$} & \multirow{2}{*}{$\begin{array}{l}\text { LC } C_{50} \\
(\mathbf{p p m})\end{array}$} & \multicolumn{2}{|c|}{ 95\% confidence limit (ppm) } & \multirow[t]{2}{*}{$\begin{array}{l}\begin{array}{l}\mathbf{L C}_{90} \\
(\mathbf{p p m})\end{array} \\
\end{array}$} & \multicolumn{2}{|c|}{ 95\% confidence limit (ppm) } & \multirow[t]{2}{*}{ df } \\
\hline & & & & LCL & UCL & & LCL & UCL & \\
\hline \multirow{4}{*}{ A. aegypti } & AgNPs & 300 & $18.79 \pm 1.01$ & $15.84 \pm 0.60$ & $21.74 \pm 1.21$ & $26.16 \pm 0.89$ & $16.21 \pm 0.42$ & $36.11 \pm 2.5$ & 3 \\
\hline & $\begin{array}{l}\text { Methanol } \\
\text { extract }\end{array}$ & 300 & $54.91 \pm 1.21$ & $51.62 \pm 3.01$ & $58.21 \pm 4.23$ & $64.57 \pm 1.24$ & $60.95 \pm 5.13$ & $68.2 \pm 4.31$ & 3 \\
\hline & $\begin{array}{l}\text { Aqueous } \\
\mathrm{AgNO}_{3}\end{array}$ & 300 & $45.91 \pm 1.32$ & $42.21 \pm 1.56$ & $49.61 \pm 3.23$ & $63.76 \pm 2.70$ & $62.14 \pm 4.35$ & $65.38 \pm 4.21$ & 3 \\
\hline & Positive & 300 & $22.68 \pm 2.47$ & & & $28.54 \pm 2.68$ & & & 3 \\
\hline
\end{tabular}

Legend: $\mathrm{n}^{\mathrm{a}}$ - means Number of larvae (triplicates: $20 \times 3 \times 5$ conc.), $\mathrm{LC}_{50}$ - Lethal concentration $50 \%$ mortality, LC $_{90}$ - Lethal concentration $90 \%$ mortality, LCL- lower confidence limits, UCL- upper confidence limits, df - degrees of freedom

Table 4: CDC Bottle Bioassay: Efficiency of methanol leaf extract synthesized AgNPs against C. quinquefasitasis

\begin{tabular}{|c|c|c|c|c|c|c|c|c|c|}
\hline \multirow{2}{*}{$\begin{array}{l}\text { Name of } \\
\text { mosquito }\end{array}$} & \multirow[t]{2}{*}{ Sample } & \multirow[t]{2}{*}{$\mathbf{n}^{\mathrm{a}}$} & \multirow{2}{*}{$\begin{array}{l}\mathbf{L C}_{50} \\
(\mathbf{p p m})\end{array}$} & \multicolumn{2}{|c|}{$95 \%$ confidence limit (ppm) } & \multirow[t]{2}{*}{$\begin{array}{l}\begin{array}{l}\text { LC90 } \\
(\mathbf{p p m})\end{array} \\
\end{array}$} & \multicolumn{2}{|c|}{$\begin{array}{l}\text { 95\% confidence limit } \\
\text { (ppm) }\end{array}$} & \multirow[t]{2}{*}{ df } \\
\hline & & & & LCL & UCL & & LCL & UCL & \\
\hline \multirow{4}{*}{$\begin{array}{l}\text { C. } \\
\text { quinquefasitasis }\end{array}$} & AgNPs & 300 & $16.02 \pm 0.34$ & $12.89 \pm 0.45$ & $19.16 \pm 0.56$ & $20.85 \pm 1.66$ & $16.41 \pm 0.58$ & $25.29 \pm 2.10$ & 3 \\
\hline & $\begin{array}{l}\text { Methanol } \\
\text { extract }\end{array}$ & 300 & $48.39 \pm 0.86$ & $42.14 \pm 3.79$ & $54.65 \pm 3.21$ & $81.56 \pm 5.9$ & $77.51 \pm 3.31$ & $85.62 \pm 4.1$ & 3 \\
\hline & $\begin{array}{l}\text { Aqueous } \\
\mathrm{AgNO}_{3}\end{array}$ & 300 & $53.83 \pm 0.86$ & $49.45 \pm 2.31$ & $58.22 \pm 1.45$ & $85.71 \pm 7.24$ & $76.21 \pm 4.29$ & $95.22 \pm 4.23$ & 3 \\
\hline & Positive & 300 & \multicolumn{3}{|c|}{$19.24 \pm 1.41$} & $22.58 \pm 2.41$ & & & \\
\hline
\end{tabular}

LCL- lower confidence limits, UCL- upper confidence limits, df - degrees of freedom

\subsection{CDC Bottle Bioassay}

The lethal dosage of synthesized AgNPs against adult mosquitos (A. stephensi, A. aegypti, and C. quinquefasciatus) were studied in the CDC bottle with different dosage range from $10-200 \mathrm{ppm}(10,50,100,150, \& 200 \mathrm{ppm})$ at 10 minutes to 3 hours interval. The results obtained are perfectly correlated with the lethal activity of AgNPs on $4^{\text {th }}$ instar larvae. The LC50 and LC90 values of AgNPs against $A$. aegypti and $C$. quinquefasitasis were $18.79 \& 26.16 \mathrm{ppm}$ and $16.02 \& 20.85$ ppm respectively than the positive control, methanol extract, and aqueous AgNO3. The absence of lethal activity was recorded on A. stephensi (Tables 3 and 4).

\section{Discussion}

Even though the chemical insecticide application is greatly active on mosquitoes, it faces some risk due to the raising of insecticide resistance and negative impacts on non-target organisms [41]. The development of insecticide resistance among mosquitos could lead to health threats worldwide, including developing and developed nations. Frequent changes in the insecticide for mosquito vector control practices lead to severe resistance mechanisms among mosquitoes [42]. Though the development of resistance among mosquitoes, frequent use of chemical insecticides has raised diverse environmental and ecological issues, such as distraction of regular biological regulator systems and adverse impacts on non-target beings and raising health issues human being [42].

The synthesis of AgNPs was preliminarily identified by the development of color changes from darkish brown to yellowish-orange due to the reduction of AgNO3 by methanol leaf extract of $O$. canum. The present findings declared that the AgNPs produced from methanol leaf extract of O.canum was analyzed using a spectrophotometer (300 to $700 \mathrm{~nm}$ ) and noticed one strong peak curve at $453 \mathrm{~nm}$, suggesting the synthesis of AgNPs at the time interval of $8^{\text {th }}$ hours. The obtained peaks of silver nanoparticles might be related to the surface plasmon vibration of AgNO3 reduction [19, 27, 28]. The outcome of the XRD specifies the occurrence of clear bands of Bragg peaks at $38.08^{\circ}$ (111) indicates Bragg's reflection, it could be related to the Face Centred Cubic (FCC) structure of AgNPs [2]. This might support the steadiness of the nanoparticles produced from methanol extract of $O$. canaum, and hence endorsing the crystallization of the organic phase present on the external of AgNPs [44, 45]. The conceivable relations between silver and bioactive molecules were analyzed by FT-IR and them accountable for the reduction and maintenance of AgNPs, indicates the occurrence of the group of hydroxyl, carboxylic, alkyl halide, and benzene ring correspondingly. The FT-IR noticeable peaks confirmed the occurrence of amide group [46]. The $1646.24 \mathrm{~cm}^{-1}$ allotted to $\mathrm{N}-\mathrm{H}$ stretching (2555.45) with $\mathrm{OH}$ groups. The fragile band at $576.16 \mathrm{~cm}^{-1}$ parallels to $\mathrm{C}=\mathrm{C}$ section in the $\mathrm{C}_{\mathrm{n}} \mathrm{H}_{2 \mathrm{n}}$ group. The obtained peaks correlate with the average peak value of certain phytochemical components $[47,48]$. Therefore, the terpenoids of plant extracts are previously reported as they have possible action to renovate the $-\mathrm{CHO}$ into $\mathrm{R}-\mathrm{COOH}$ in nanoparticle $[31,32]$. 
The SEM analysis report clearly states that the shape of synthesized AgNPs as spherical and elongated in appearance and size ranges from 32.75 to $78 \mathrm{~nm}$ with the uniform surface distribution. Similar kinds of results were reported by Suganya et al. [47]. They produced AgNPs using Nelumbo nucifera leaf extract with shape like triangle, spherical and truncated triangles with 25 to $80 \mathrm{~nm}$ in size. The EDaX peak about 72.64 to the binding energies, and it confirms the untainted form of AgNPs. The EDaX verified AgNPs produced from methanol extracts exhibited a solid signal of silver from $3 \mathrm{keV}$. The Xray discharge might be derived from biomolecules like carbohydrates, enzymes, etc. which exists in the leaves of $O$. canaum. Tian et al. [45] have considered the flavonoids component of lotus leaves for silver nanoparticle synthesis.

Biological components play a significant part in reducing corresponding metal nanoparticles as like silver [47, 48]. Hence, the present study result confirms that the phytochemical contents of $O$. canum could play the most significant role reduction of AgNO3 to AgNPs. Therefore, in addition to the existing vector control measures, AgNPs synthesized from plant extracts could play an important role in controlling mosquito vector-borne diseases such as malaria and filariasis. The larvae mortality potential of synthesized AgNPs on larvae of $A$. aegypti, A. stephensi, and $C$. quinquefasciatus were studied. There was no lethal activity against larvae of $A$. stephensi. The very low LC50 and LC90 values were noted for A. aegypti and C. quinquefasciatus as $17.03 \& 24.18 \mathrm{ppm}$ and $14.89 \& 20.65 \mathrm{ppm}$ respectively than the positive control (Table 3 \& 4). Similarly, it shows better activity on adult mosquitos' namely $A$. aegypti and $C$. quinquefasciatus with minimum LC50 values (Table $3 \& 4$ ). Our results are partially correlated with the report of Suganya et al. [47] they produced NPs from Leucas aspera revealed prospective larvicidal action on A. aegypti larvae with LC50 and LC90 $22.21 \& 27.32$ ppm.

Further, Parthiban et al. [37] reported green synthesized silver nanoparticles from aqueous leaf extract of Annona reticulata and which possess excellent larvicidal activity on larvae of Aedes aegypti. The mortality of larvae and adult mosquito by AgNPs might be the due to the disintegration of sulfur or phosphorous components of biomolecules. This resulting failing enzymes activities leads to decrease in ATP synthesis and condenses the cellular membrane permeability which origins the loss of the cell metabolisms and leads to cell lysis $[25,8,36]$. For the environmental protection and mosquito control management, the green synthesis based AgNPs, which have potential mortality against mosquito vectors, could be suitable for pest management and to minimize the mosquito vector-borne diseases.

\section{Conclusion}

The overall results conclude that the AgNPs were fruitfully synthesized using methanol leaf extract of $O$. canaum. The synthesized AgNPs are characterized and confirmed through the UV-Vis spectrum, XRD, SEM, EDaX, and FTIR. The low dosage of AgNPs showed outstanding mosquito larvicidal activity on $A$. aegypti as LC50 $=17.03$ with $\mathrm{LCL}=14.448$ \& $\mathrm{UCL}=19.6286 \mathrm{ppm}$, it followed by $C$. quinquefasciatus as LC50 $=14.89$ with $\mathrm{LCL}=11.721 \& \mathrm{UCL}=18.0621 \mathrm{ppm}$. These results declared that the AgNPs produced from methanol leaf extract of $O$. canum have outstanding mosquito control potential at both larvae and adult stage. The prominence of the present findings exists in the probability that the production of NPs attached with plant bioactive compounds, which might enhance the NPs activity to control mosquito vectors. Thus could be act as replacement for chemical insecticides and possibilities of reducing environmental pollution.

\section{Authors' contributions}

The author JMM planned the outline of the research work, carried out the research, NM prepared the manuscript. GR and SK support result analysis and manuscript editing, MSS supervise the research work. The authors have read and approved the final manuscript.

\section{Acknowledgment}

The first and third authors are thankful to the PG and Research Centre in Biotechnology, MGR College, Hosur, Tamilnadu, India, and the third author is thank full to Molecular Entomology Lab, Department of Biotechnology, Periyar University, Salem, Tamilnadu, India for offering a sophisticated lab facility for successful completion of this study.

\section{Declarations}

The authors declare the following consent

\section{Funding}

Not applicable

\section{Conflict of Interest}

The authors declare that there is no conflict of interest regarding the publication of this manuscript.

\section{Ethics approval}

Not applicable

\section{Consent to/for publication}

Not applicable

\section{Availability of data and materials}

The detailed methodology and analytical data of the present findings are available from the corresponding author on reasonable request.

\section{Code availability}

Not applicable

\section{References}

1. Narayanan M, Devarajan N, He Z, Kandasamy S, Ashokkumar V, Raja R, Carvalho IS. Assessment of microbial diversity and enumeration of metal tolerant autochthonous bacteria from tailings of magnesite and bauxite mines. Materials Today: Proceedings. 2020 Sep 11

2. Mathiyazhagan N, Natarajan D. Impact of mine waste dumps on growth and biomass of economically important crops. Journal of environmental biology. 2012 Nov 1;33(6):1069.

3. Zhang B, He Z, Chen H, Kandasamy S, Xu Z, Hu X, et al. Effect of acidic, neutral and alkaline conditions on product distribution and biocrude oil chemistry from hydrothermal liquefaction of microalgae. Bioresource technology. 2018;270:129-37.

4. Mathiyazhagan N, Danashekar K, Natarajan D. Amplification of biosurfactant producing gene (rhlB) from Pseudomonas aeruginosa isolated from oil contaminated soil. International Journal of Pharma and Bio Sciences. 2011;2(1)

5. Feng H, He Z, Zhang B, Chen H, Wang Q, Kandasamy S. Synergistic bio-oil production from hydrothermal co-liquefaction of Spirulina platensis and $\alpha$-Cellulose. Energy. 2019;174:1283-91.

6. Narayanan M, Devarajan N. Bioremediation on effluents from magnesite and bauxite mines using Thiobacillus spp. and Pseudomonas spp. Journal of Bioremediation and Biodegradation. $2011 ; 2(1)$.

7. Narayanan M, Devarajan N. Metal and antibiotic tolerance potentiality of Acidithiobacillus spp and Pseudomonas spp from 
waste dumps of bauxite and magnesite mines. Archives of Applied Science Research. 2012;4(1):616-22.

8. Chen H, He Z, Zhang B, Feng H, Kandasamy S, Wang B. Effects of the aqueous phase recycling on bio-oil yield in hydrothermal liquefaction of Spirulina Platensis, $\alpha$-cellulose, and lignin. Energy. 2019;179:1103-13.

9. Mathiyazhagan N, Natarajan D. Phytoremediation efficiency of edible and economical crops on waste dumps of bauxite mines, Salem district, Tamil Nadu, India. InOn a Sustainable Future of the Earth's Natural Resources 2013 (pp. 493-508). Springer, Berlin, Heidelberg.

10. Zhang B, Chen J, He Z, Chen H, Kandasamy S. Hydrothermal liquefaction of fresh lemon-peel: parameter optimisation and product chemistry. Renewable Energy. 2019;143:512-9.

11. Mathiyazhagan N, Natarajan D. Physicochemical assessment of waste dumps of Magnesite and Bauxite Mine in summer and rainy season. International Journal of Environmental Sciences. 2012;2(4):2243-52.

12. Kandasamy S, Zhang B, He Z, Chen H, Feng H, Wang Q, et al. Hydrothermal liquefaction of microalgae using $\mathrm{Fe} 3 \mathrm{O} 4$ nanostructures as efficient catalyst for the production of bio-oil: Optimization of reaction parameters by response surface methodology. Biomass and Bioenergy. 2019;131:105417.

13. Krishnamoorthi M, Malayalamurthi R, He Z, Kandasamy S. A review on low temperature combustion engines: Performance, combustion and emission characteristics. Renewable and Sustainable Energy Reviews. 2019;116:109404.

14. Narayanan M, Ranganathan M, Subramanian SM, Kumarasamy S, Kandasamy S. Toxicity of cypermethrin and enzyme inhibitor synergists in red hairy caterpillar Amsacta albistriga (Lepidoptera: Arctiidae). The Journal of Basic and Applied Zoology. 2020 Dec;81(1):1-8.

15. Kandasamy S, Sundararaj S. Engine performance and emission profile of Simarouba glauca biodiesel and blends. International Journal of Oil, Gas and Coal Technology. 2020;25(2):202-17.

16. Narayanan M, Kumarasamy S, Ranganathan M, Kandasamy S, Kandasamy G, Gnanavel K. Enzyme and metabolites attained in degradation of chemical pesticides $\beta$ Cypermethrin by Bacillus cereus. Materials Today: Proceedings. 2020 Jul 1.

17. He Z, Wang B, Zhang B, Feng H, Kandasamy S, Chen H. Synergistic effect of hydrothermal Co-liquefaction of Spirulina platensis and Lignin: Optimization of operating parameters by response surface methodology. Energy. 2020:117550.

18. Mathiyazhagan N, Natarajan D, Suresh K. Impact of waste dumps of mines on plants in genomic \& bio molecules level. Mesopotamia Environmental Journal. 2015;2(1):33-45

19. Narayanan M, Devarajan N, Kandasamy G, Kandasamy S, Shanmuganathan R, Pugazhendhi A. Phytoremediation competence of short-term crops on magnesite mine tailing. Chemosphere. 2020 Oct 21:128641.

20. Zhang B, Chen J, Kandasamy S, He Z. Hydrothermal liquefaction of fresh lemon-peel and Spirulina platensis blending-operation parameter and biocrude chemistry investigation. Energy. 2020;193:116645.

21. Narayanan M, Kandasamy G, He Z, Kandasamy S, Alfarhan AH, Pugazhendhi A. Phytoextraction competence of J. curcas L. on ore waste dump of the bauxite mine under the influence of multi potential Bacillus cereus. Environmental Technology \& Innovation. 2020 Oct 28:101221.

22. Soman S, Kumarasamy S, Narayanan M, Ranganathan M. Biocatalyst: phytase production in solid state fermentation by OVAT Strategy. Bioin. Res. App. Chem.. 2020;10:6119-27.

23. Kandasamy S, Zhang B, He Z, Chen H, Feng H, Wang Q, et al. Effect of low-temperature catalytic hydrothermal liquefaction of Spirulina platensis. Energy. 2020;190:116236.

24. Natarajan D. Assessment of physicochemical and heavy metals from waste dumps of magnesite and bauxite mines. Electronic Journal of Environmental, Agricultural and Food Chemistry (EJEAFChe). 2011 Nov 25;10(11):3076-82.

25. Mathiyazhagan N. Metal extraction competence of plants on waste dumps of magnesite mine, Salem District, South India. Journal of Mining and Environment. 2013 Oct 1;4(2):113-24.

26. Narayanan M, Kumarasamy S, Ranganathan M, Kandasamy S, Kandasamy G, Gnanavel K, Mamtha K. Production and characterization of polyhydroxyalkanoates synthesized by E. coli Isolated from sludge soil. Materials Today: Proceedings. 2020 Jun 30 .

27. Soman S, Suresh K, Mathiyazhagan N, Muthusamy R. Chemically defined medium for the production of Phytase by Hanseniaspora guilliermondii S1, Pichia fermentans S2 and its secondary structure prediction of 16S rRNA. Bioin. Res. App. Chem.. 2020;10:626272.

28. Mathiyazhagan N, Natarajan D. Optimization of RAPD-PCR Protocol to Screen Jatropha Curcas and Gossypium Hirsutum Grown in Metal Contaminated Soil.2011;

29. Mathiyazhagan N, Suresh K, Deepa CA. Case study on novel natural remedy (Trichosanthes dioica Roxb.) against bacillary white diarrhea in broiler chickens. International Journal of Petrochemical Science \& Engineering. 2018;3(2):71-3.

30. Kumarasamy S, Subramanian V, Narayanan M, Ranganathan M. Microbial stereo inversion of (R) 3 Chloro-1, 2-propandiol by Wickerhamomyces anomalous MGR6-KY209903. Biointerface Res. App. Chem.. 2020;10:6157-66

31. Ramamurthy CH, Sampath KS, Arunkumar P, Kumar MS, Sujatha V, Premkumar K, Thirunavukkarasu C. Green synthesis and characterization of selenium nanoparticles and its augmented cytotoxicity with doxorubicin on cancer cells. Bioprocess and biosystems engineering. 2013 Aug 1;36(8):1131-9.

32. Murugan JM, Ramkumar G, Shivakumar MS. Insecticidal potential of Ocimum canum plant extracts against Anopheles stephensi, Aedes aegypti and Culex quinquefasciatus larval and adult mosquitoes (Diptera: Culicidae). Natural Product Research. 2016 May 18;30(10):1193-6.

33. Narayanan M, Kandasamy S, Kumarasamy S, Gnanavel K, Ranganathan M, Kandasamy G. Screening of polyhydroxybutyrate producing indigenous bacteria from polluted lake soil. Heliyon. 2020 Oct 1;6(10):e05381.

34. Ghoran SH, Firuzi O, Jassbi AR. Phytoconstituents from the Aerial Parts of Salvia dracocephaloides Boiss. and their Biological Activities. Journal of Environmental Treatment Techniques. 2020;8(4):1274-8

35. Minjas JN, Sarda RK. Laboratory observations on the toxicity of Swartzia madagascariensis (Leguminosae) extract to mosquito larvae. Transactions of the Royal Society of Tropical Medicine and Hygiene. 1986 Jan 1;80(3):460-1.

36. Huang J, Li Q, Sun D, Lu Y, Su Y, Yang X, Wang H, Wang Y, Shao W, He N, Hong J. Biosynthesis of silver and gold nanoparticles by novel sundried Cinnamomum camphora leaf. Nanotechnology. 2007 Feb 6;18(10):105104.

37. Parthiban E, Manivannan N, Ramanibai R, Mathivanan N. Green synthesis of silver-nanoparticles from Annona reticulata leaves aqueous extract and its mosquito larvicidal and anti-microbial activity on human pathogens. Biotechnology Reports. 2019 Mar 1;21:e00297.

38. Rahuman AA, Bagavan A, Kamaraj C, Vadivelu M, Zahir AA, Elango G, Pandiyan G. Evaluation of indigenous plant extracts against larvae of Culex quinquefasciatus Say (Diptera: Culicidae). Parasitology Research. 2009 Feb 1;104(3):637.

39. Ramkumar G, Shivakumar MS. Laboratory development of permethrin resistance and cross-resistance pattern of Culex quinquefasciatus to other insecticides. Parasitology research. 2015 Jul 1;114(7):2553-60.

40. WHO. Report of the WHO informal consultation on the evaluation on the testing of insecticides CTD/WHO PES/IC/96. 1996.

41. Liu N, Liu H, Zhu F, Zhang L. Differential expression of genes in pyrethroid resistant and susceptible mosquitoes, Culex quinquefasciatus (S.). Gene. 2007 Jun 1;394(1-2):61-8.

42. Yang YC, Lee SG, Lee HK, Kim MK, Lee SH, Lee HS. A piperidine amide extracted from Piper longum L. fruit shows activity against Aedes aegypti mosquito larvae. Journal of agricultural and food chemistry. 2002 Jun 19;50(13):3765-7.

43. Lincy A, Jegathambal P, Mkandawire M, MacQuarrie S. Nano Bioremediation of Textile Dye Effluent using Magnetite Nanoparticles Encapsulated Alginate Beads. Journal of Environmental Treatment Techniques. 2020;8(3):936-46.

44. Kim KJ, Sung WS, Suh BK, Moon SK, Choi JS, Kim JG, Lee DG. Antifungal activity and mode of action of silver nano-particles on Candida albicans. Biometals. 2009 Apr 1;22(2):235-42. 
45. Tian N, Liu Z, Huang JA, Luo G, Liu S, Liu X. Isolation and preparation of flavonoids from the leaves of Nelumbo nucifera Gaertn by preparative reversed-phase high performance liquid chromatography. Se pu= Chinese journal of chromatography 2007 Jan 1;25(1):88-92.

46. Vadivelu B, Meyyazhagan A, Palanisamy S, Anand V, Chelliapan KK. Synthesis of Silver Nanoparticles from Fish Scale Extract of Cyprinus carpio and its Decolorization Activity of Textile Dyes. Journal of Environmental Treatment Techniques. 2020;8(3):870-

47. Suganya G, Karthi S, Shivakumar MS. Larvicidal potential of silver nanoparticles synthesized from Leucas aspera leaf extracts against dengue vector Aedes aegypti. Parasitology research. 2014 Mar 1;113(3):875-80.

48. Benelli G, Mehlhorn H. Declining malaria, rising of dengue and Zika virus: insights for mosquito vector control. Parasitology research. 2016 May 1;115(5):1747-54 